\title{
LA VOLUNTAD DE EXISTIR: HISTORIAS DE VIOLENCIA EN UNA COLECTIVIDAD DE MUJERES TRANS
}

\section{Resumen}

En este artículo, se analizan diferentes formas de violencia que enfrenta una comunidad de mujeres trans (trabajadoras y extrabajadoras sexuales), en San José, Costa Rica; así como sus estrategias colectivas de resistencia en la defensa de sus vidas y su identidad. El texto se construye con la metodología de narrativas discontinuas, a partir de los registros recabados durante tres años de investigación militante y proceso etnográfico que desarrollé junto a esta comunidad. La metodología busca tejer los relatos múltiples de las participantes para formar una narrativa en la que se reconstruye la historia desde la perspectiva de las protagonistas: las sobrevivientes, las víctimas, las rebeldes insumisas.

Palabras clave: Mujeres trans, violencia, trabajo sexual, biopolítica, resistencia.

\begin{abstract}
Resumo
A vontade de existir: Histórias de violência e resistência numa comunidade de mulheres trans

Neste artigo, analisam-se diferentes formas de violência que uma comunidade de mulheres trans (trabalhadoras e ex trabalhadoras sexuais) enfrenta, em San José, Costa Rica; além das suas estratégias coletivas de resistência na defesa das suas vidas e das suas identidades. No texto, utiliza-se a metodologia das narrativas descontinuas, a partir dos registos recolhidos durante os três anos de investigação militante e de processo etnográfico que desenvolvi com esta comunidade. A metodologia procura tecer os relatos diversos das participantes para formar uma narrativa que reconstrua a história a partir da perspectiva das protagonistas: as sobreviventes, as vítimas, as rebeldes insubmissas.
\end{abstract}

Palavras-chave: Mulheres trans, violência, trabalho sexual, biopolítica, resistência.

\section{Abstract}

The will to exist: Stories of violence and resistance in a community of trans women

This article analyzes different forms of violence faced by a community of trans women (sex workers and former sex workers), in the city of San José, Costa Rica; as well as their collective strategies for resisting and defending their lives and their identities. Using a discontinuous narratives technique, in this text, I seek to interconnect stories registered during the three years of militant research and ethnographical process I developed with this community. This approach pursues to knit the narrations of multiple participants, in order to reconstruct the history of this community from their own perspective: as survivals, as victims, as rebels.

Keywords: Trans women, violence, sex work, biopolitics, resistance.

Escuela de Psicología, Facultad de Ciencias Sociales, Universidad de Costa Rica, San Pedro de Montes de Oca, 2060 San José, Costa Rica.

Dirección postal: 23 Avenue du Docteur Antoine Lacroix, 94270, Le Kremlin-Bicêtre, Francia.

Correo electrónico: mar.fournierp@gmail.com 


\section{Introducción}

Este texto es producto de las reflexiones colectivas de un grupo de mujeres trans con quienes me involucré en un intenso proceso de investigación afectiva y militante que comenzó en 2014 y continua sin miras a terminar. ${ }^{1}$

Como parte de esto, surgió la tesis titulada Género, Clase y Afectividad: vínculos y comunicación en una comunidad de trans (Fournier 2017), que recorre estas y otras narrativas alrededor de la historia de luchas, gloria, afectos, sororidad y resistencias que han gestado las mujeres trans trabajadoras y extrabajadoras sexuales de la ciudad de San José durante las últimas décadas.

En este artículo, se recogen los principales resultados alrededor de la pregunta sobre cuáles son las formas particulares de violencia que han sufrido las mujeres trans en la ciudad de San José. Se construye con relatos de quienes han logrado sobrevivir algunas de las peores formas de violencia y tortura que ha conocido la democracia costarricense.

Los testimonios que aquí se exponen fueron registrados a través de observación participante y algunas entrevistas abiertas, durante las «tardes de café». Se trata de un espacio informal e íntimo, donde un grupo de alrededor de 25 mujeres trans entre los 25 y los 64 años que ejercen o ejercieron el trabajo sexual se reúnen en el local que les facilita la organización Transvida, ${ }^{2}$ a conversar, mirar fotografías y recordar tiempos pasados y hermanas caídas. Se trata de un espacio que Segato (2016) describiría como política vincular femenina:

Hay que hacer la política del día a día, por fuera del Estado: retejer el tejido comunitario, derrumbar los muros que encapsulan los espacios domésticos y restaurar la politicidad de lo doméstico propia de la vida comunal. Es de esta politicidad y de esas tecnologías vinculares que surgirá el formato de la acción política capaz de reorientar la historia en la dirección de una felicidad mayor, pautada por el fin de la prehistoria patriarcal de la humanidad. Es la política de las mujeres la que ahora tiene su vez. (Segato 2016, 106)

A mediados de 2017 fui invitadx a participar en este espacio. Ellas manifestaron interés en escribir su historia, por lo que entre julio y setiembre de 2017 las acompañé todos los viernes por la tarde para escucharlas recordar y celebrar su

1 Durante estos años, he desarrollado cualquier trabajo de apoyo que necesiten las mujeres de esta comunidad, desde conducir un auto para llevarlas a actividades, digitar datos y redactar cartas e informes, hasta patrullar las calles en momentos de crisis de violencia. Ha sido un proceso largo que nos permitió desarrollar relaciones de confianza, que se desmarcan de los contratos verticales de investigación, y posibilitan hoy una etnografía de la vida cotidiana. Para una descripción detallada sobre el complejo proceso en el que construimos nuestros acuerdos políticos, afectivos y de investigación, ver el capítulo 8 en Fournier (2017).

Organización de base de mujeres trans. 
existencia. Aceptaron que grabara las conversaciones: diálogos desordenados y múltiples, donde mis intervenciones se limitaban a algunas preguntas puntuales cuando era necesario, o bien, a brindar palabras de apoyo y agradecimiento a quienes me estaban compartiendo sus recuerdos de dolor, miedo o ternura.

Para la sistematización, opté por la metodología de narraciones discontinuas ${ }^{3}$ para evitar traducir o interpretar sus vivencias, y dar lugar a sus palabras y sus diálogos coloquiales, que la historia tantas veces ha querido silenciar. Mi función es también dialógica, busco tejer (sin jerarquizar) algunos de sus testimonios y reflexiones con referentes de teorías sobre el poder (como Foucault 2008) y la violencia (como Segato 2003), desde un enfoque transfeminista e interseccional. ${ }^{4}$ En este artículo que se inscribe dentro del campo de los estudios trans ${ }^{*}$, no pretendo establecer la verdad unívoca y categórica sobre las formas de violencia que enfrenta esta población, sino dar lugar a la memoria colectiva, a los afectos y a los saberes localizados de esta comunidad sobre su propia historia.

\section{Narrativas de la violencia}

Costa Rica ha logrado posicionar, tanto dentro como fuera de sus fronteras, el imaginario de un país pacífico con una larga y profunda tradición democrática. El mito de la excepcionalidad hace pensar que Costa Rica está lejos de los conflictos sociales que enfrentan los pueblos hermanos de la región Centroamericana. Es una peligrosa paradoja. Por un lado, es cierto que en Costa Rica no sufrimos los niveles y las formas complejas de violencia que enfrentan otros países donde las políticas neoliberales, la corrupción estatal, el narcotráfico, las masculinidades tóxicas, el racismo y la colonialidad han formado un coctel letal. Incluso dentro de la colectividad de mujeres trans podemos constatar esta realidad: San José recibe cada año varias migrantes que vienen huyendo de las realidades cruentas de sus países (OIM 2016), y aunque Costa Rica está lejos de ser un paraíso trans, las condiciones son considerablemente menos inseguras que en otros países vecinos.

3 Metodología que «se ha implementado sin construir un texto único y continuo sino dejando que las diferentes voces que aparecen en él mantengan su autonomía. De esta manera se intenta no homogeneizar las propuestas realizadas, no tratarlas como expresión de un pensamiento único sino mostrar que se puede ser incoherente o expresar puntos de vistas diferentes en un mismo discurso» (Biglia y Bonet 2009, 13). En este sentido, transcribo sus expresiones tal como fueron registradas, sin «correcciones» de estilo ni censura, con el fin de que sean sus palabras las que irrumpan en nuestros espacios académicos, y no la academia la que las modere o edulcore.

4 El concepto de interseccionalidad, posicionado por feministas como Kimberlé Crenshaw (1989) propone una lectura sobre la forma en que los sistemas de dominación oprimen de formas distintas, simultáneas y combinadas a una misma persona. En este caso, género, clase, sexualidad y, en algunos casos, raza se entretejen para crear condiciones de opresión profundamente violentas para las participantes. 
Sin embargo, en los relatos de estas mujeres pude identificar distintas formas de violencia, con algunas de las expresiones más crueles que he conocido en el país. Los modos han ido transformándose con el tiempo, pero todas guardan en común una raíz que se ancla en el potente nudo de la clase, el género y la sexualidad. Capitalismo y patriarcado se funden en amalgama letal contra esta colectividad de mujeres trans.

Por décadas, la violencia que estas mujeres enfrentan ha sido legitimada y hasta institucionalizada en manos de autoridades policiales y del sistema de salud costarricense. Con los años, estas prácticas han dejado de ser prescritas por la ley, pero la violencia sigue siendo estructural. Aun cuando ya no existen motivos legales para detener y castigar a una mujer trans, el sistema sigue permitiendo la impunidad judicial y social de los abusos policiales y las torturas que sufren en la calle a manos de desconocidos que atienden el mandato masculino.

La violencia que sufren las mujeres trans empobrecidas en la ciudad de San José, como en tantas otras, es una violencia estructural que busca el control de sus cuerpos, la aniquilación de sus subjetividades y la desaparición de sus identidades.

\section{Disciplina: el castigo de lo abyecto}

La forma más antigua y persistente que ha tomado la violencia contra esta colectividad es lo que Foucault (2002) denomina dispositivo disciplinario, una forma de ejercer el poder donde el castigo juega un doble rol disciplinar: sancionar a quien se sale de la norma y aleccionar a la sociedad como público general.

La historia que narran estas mujeres comienza en la década de 1970, no porque antes no existieran mujeres trans - tenemos incluso registros en la prensa de principios de siglo XX de existencias que hoy llamaríamos trans (Fournier 2017) -, sino porque las que sobreviven para contar su historia empezaron a afirmar su existencia en esta década. Fueron tiempos de crueldad disciplinaria, donde la criminalización, el encierro y el castigo físico marcaban las formas en que el Estado lidiaba con las existencias trans.

MF: ¿Y se las cargaban por estar vestidas?

Alexa: Por todo: sodomía, escandalosas, irrespeto a la autoridad, faltas a la moral.

MF: Ellos se inventaban lo que fuera...

Rosario: Cualquier cosa le ponían a uno.

Aun cuando el modelo criminológico dominante era el disuasorio y en los centros penitenciarios se confundía la penitencia con la justicia, para encerrar a las mujeres trans era necesario primero hacer de su existencia un motivo de detención. Las autoridades se ampararon en la Ley contra la Vagancia, la Mendicidad y 
el Abandono (derogada finalmente el 1994) para justificar la detención y encarcelamiento de las mujeres trans. Una mujer con pene no podía ser vista a plena luz del día en un espacio público, porque su existencia misma era considerada motivo de castigo y detención.

De la calle a la corte, de la corte a la cárcel, de la cárcel a la calle, y otra vez. Estas mujeres cumplían días de prisión en un centro penitenciario para hombres, en espacios especialmente designados para estas, con condiciones aún más insalubres que las del resto de la prisión (Fournier 2017).

Sandra: No, pero para la información de ustedes: yo tengo en la Corte 139 pasadas. ¿Creen ustedes que eso tiene sentido? Era en base a esos partes infundados que hacían ellos. Que faltas a la moral, vagancia...

Laura: Vestir prendas femeninas.

Sandra: Según ellos, para ellos eso era inmoral, era anti... ético, ¿no?

Las detenciones en nombre de la moral y las buenas costumbres iban siempre acompañadas de una dosis de humillación. Es el componente comunicativo del poder disciplinario, ese que adiestra tanto el cuerpo que castiga como el que observa.

Laura: Hasta nos daban «paseos». Paseos por el parque donde está la biblioteca que tiene una gran pendiente. $Y$ se venían desde arriba como la montaña rusa. Y todas pegábamos en el techo del cajón, ${ }^{5}$ para golpearnos, para agredirnos.

Adriana: Sí, muy duro.

Sonia: Lo dejaban botado allá por el culo del mundo. ${ }^{6}$

Laura: ¡Horrible!

Alexa: [...] Una detención exclusiva para nosotras. [...] Yo me acuerdo que pasaban los carros viejos. Y nos cargaban, nos llevaban a Coronado, ${ }^{7}$ digamos a las 9 de la noche y nos soltaban a las 2 de la mañana, 3 de la mañana.

Julieta: Se las llevaban a chancheras ${ }^{8}$ en Coronado. A las chancheras las llevaban y las tiraban ahí. Las desnudaban y las mojaban con barro. Y después las tiraban a las 6 de la mañana. Burlada y todo, y cuando se montaban en los buses aquellos monstruos, porque todas llenas de barro y todo. ¡ Uy no, qué fuerte!

Una vez en el centro penitenciario, la humillación continuaba haciendo uso del asco como castigo, al que le sumaba el despojo de su feminidad:

Sandra: Lo metían a uno y le ponían un buzo. Lleno de piojos.

El «cajón» se refiere a la parte trasera de la patrulla donde llevan a las personas detenidas.

Expresión que refiere un lugar muy lejano.

Cantón que se ubica en la cima de una montaña a unos $10 \mathrm{~km}$ del centro de la ciudad.

Chancera: porqueriza. 
Sofía: También a muchas las dejaron pelonas. Yo fui la única que no me dejé cortar el pelo. Me agarré como con 20. Y me hicieron así papilla en el suelo. Con un ojo morado y todo, pero no me lo dejé cortar.

Y a todo esto le seguían las torturas:

Victoria: Los policías nos violaban. Nos agarraban y nos secuestraban, nos tiraban orines, miados, allá en los calabozos. [...] Sí, me llevaron a la Peni. ${ }^{9}$ Tenía 13 primaveras. Y me llevaron ahí a la Peni y en la Peni estaban los llamados Hijos del Diablo. ${ }^{10}$ Hicieron fila india donde mí.

Con apenas trece años, esta mujer sufrió una violación en grupo con la total complicidad de los guardias penitenciarios y del sistema judicial. Cuentan que los mismos guardias aprovechan para hacer negocio con sus cuerpos:

Cecilia: A mí me compraron por 50 colones, ${ }^{11}$ el Negro Chita en la Peni.

Rosa: A mí también.

MF: ¿Cómo, cómo?

Rosa: 50 colones pa rajala. ${ }^{12}$

Cecilia: Es que, cuando uno llegaba a la Peni, los maleantes de ahí nos compraban. Entonces el Negro Chita pagó 50 colones por mí.

MF: ¿Pero a quién se los pagó? ¿A usted?

Cecilia: Al guarda.

MF: ¡Al guarda! O sea, el guarda la vendía como si usted fuera un chunche. ${ }^{13}$ ¿Así?

Cecilia: Entoes, el Negro Chita, yo estuve presa 3 días y los 3 días fueron 3 veces diarias que...

Cuando no las vendían, jugaban al boxeo o al tiro al blanco con ellas. Despojadas de su estatus de humanidad, sus cuerpos eran objetos despreciables con los que estos hombres afirmaban su hombría (Segato, 2003) mientras mataban el aburrimiento adentro de la prisión.

\section{Biopolítica: control de la vida}

La ciencia, la estadística y la medicina empujan hacia un giro discursivo en el ejercicio del poder. Al lado de la vigilancia y el castigo, el control de los cuerpos comienza a planificarse, justificarse e implementarse por otros medios. En Costa

\footnotetext{
Penitenciaría Central

Pandilla que se caracterizó por sus formas violentas y cruentas de accionar.

En la década de 1970, 50 colones equivalían a 0,17 dólares.

Expresión que refiere a las violaciones que sufrían, específicamente a la penetración anal.

«Chunche»: costarriqueñismo que quiere decir cosa.
} 
Rica, el auge de la biopolítica golpea con fuerza a esta y otras poblaciones en las décadas de 1980 y 1990.

La biopolítica busca regular la vida bajo los parámetros de la normalidad. Más que normar, pretende normalizar. No busca «obtener la obediencia de los súbditos a la voluntad del soberano, sino influir sobre cosas aparentemente alejadas de la población, pero que, según hacen saber el cálculo, el análisis y la reflexión, pueden actuar en concreto sobre ella» (Foucault 2008, 95).

La corporalidad es el sustrato para el biopoder, desde una racionalidad política que administra la vida a través de la gestión de los cuerpos. Si el dispositivo disciplinario se caracteriza por su potencial letalidad, la biopolítica busca más bien mantener la vida, preservarla, en tanto es la condición necesaria para el ejercicio del poder (Foucault 2008).

En este caso, encontramos al menos dos grandes vertientes por las que se encausan las corrientes del biopoder: el discurso que plantea la existencia trans como una amenaza para la salud pública y la vida (sintetizada en una política higienista), y el control mismo de los cuerpos trans, a través de la medicina y la industria farmacéutica - eso que Paul B. Preciado (2008) llamaría farmacopornopoder.

El higienismo social volvió con fuerza a Costa Rica en la década de 1980, nutrido por la moral conservadora característica de la idiosincrasia costarricense y su Estado confesional. Sobre estas mujeres trans se depositaban los peores estereotipos alrededor de la sexualidad como suciedad: se les consideraba homosexuales (en un contexto en que la homosexualidad era entendida como perversión, patología y pecado), eran trabajadoras sexuales (en una sociedad que todavía hoy es profundamente misógina y patriarcal), y se presumía (sin que existiesen estudios epidemiológicos para sustentarlo) que sus cuerpos albergaban todo tipo de infección de transmisión sexual (ITS) y posteriormente también el VIH.

Se les señalaba como foco de infección. A la persecución policial ahora se sumaba el Ministerio de Salud que acechaba y hostigaba su existencia. Como a las trabajadoras sexuales cisgénero, se les impuso el deber de portar un carnet de dispensario. «Era como un permiso para putear», dice Alexa. Podríamos decir que era un permiso para existir, un documento que debían validar cada 15 días, donde certificaba que se encontraban libres de ITS. La que fuera encontrada sin carnet o con el carnet vencido, era detenida y procesada, por lo que debían someterse a este estricto control para poder circular por la ciudad.

Sofía: No pero cuando salió la enfermedad del SIDA no se acuerda que traían ese montón de portones para llevarnos a todas a... a la Sabana. ${ }^{14}$ A la Sabana que había una rueda así de pacos, ${ }^{15}$ yo no sé si usted se acuerda.

Parque metropolitano.

Pacos: forma despectiva de nombrar a la policía. 
Alexa: Era como para hacer un tamizaje.

MF: ¿Pero las llevaban obligadas?

Alexa: ¡Sí, claro!

Sofía: A la fuerza.

Sonia: Todo mundo corría por San José.

Sofía: Inclusive, brincándose los techos y todo porque...

Se las cargaban en grupos grandes y las llevaban a una especie de corral humano en el parque metropolitano, donde las obligaban a tomarse muestras de sangre y a someterse a un examen físico de boca, ano y genitales. Esta inspección no iba dirigida a promover la salud en la población de mujeres trans, sino a cuidar a la ciudadanía de la cual ellas estaban excluidas. Su existencia era más bien despreciada, y no dudan que el deseo de muchos era exterminarlas.

Laura: Porque eras un foco de contagio. Y cuando empezó el VIH a aflorar, aquello era... Era algo tremendo, de verdad. Si hubieran tenido la oportunidad como fue las cámaras de gas, lo hubieran hecho.

Adriana: Ah sí.

Sofía: ¡Ah sí! Nos vieramos ido más de una.

Llegamos a la otra vertiente, donde la medicina no persigue, sino que seduce. En manos de profesionales inescrupulosos, docenas de mujeres trans han sufrido una estafa mortífera. Ante la negativa que algunos médicos conservadores sostienen de poner implantes de seno a una mujer trans, otros encontraron un negocio fácil. En un contexto donde la mayoría de estas mujeres viven bajo la línea de pobreza, un procedimiento que promete en un par de horas unos senos a bajo costo, es una oferta que resulta un sueño hecho realidad.

Elena: Este Joaquín era un señor que vivía frente al Líbano, el que se encargaba de ponernos aceite.

Rosa: Muchas se pusieron, verdad.

Elena: A muchas se les fue a otras partes del cuerpo y fallecieron. Pero otras aún lo conservan y se ven bonitas.

MF: ¿Y eran caros esos tratamientos?

Varias: No, no.

Rosa: Diay, ¿cuánto cuesta el aceite de la cocina?

Andrea: El aceite mineral era barato.

Daniela: No, pero al viejo Quincho uno le daba dos pesos y ya le salía con unas tetas así.

Rosa: Claro, de la noche a la mañana salías bien bella, así.

Daniela: Cuál de la noche a la mañana: dos horas, tres horas, ya.

Elena: Las más osadas recurrimos también a inyecciones de aceite mineral. Y el famoso, hubo tiempo en el 70, otras también, se inyectaban para tener más fuerza con las hormonas. También unas decían por ahí que se inyectaban aceite hasta de avión. 
Lo que no les explicaron es que el aceite no estaba contenido como estaría el silicón en un implante, y por ende con el tiempo la fuerza de gravedad provoca que comiencen a derramarse por el cuerpo y estancarse en las caderas, testículos, tobillos y pies.

Rosa: Unas se murieron de cáncer, en el cuerpo. Como la Samantha, y Estela también se murió de eso.

Con dolor, vergüenza y rabia lamentan hoy la estafa que les deja marcas irreparables. En diálogo con Preciado (2008), en los cuerpos trans podríamos hablar de un panóptico inyectable. La aguja que penetra sus carnes inocula en sus cuerpos el aceite que es a la vez recompensa y castigo, vida elegida y sentencia muerte. En la miseria, el «panóptico que se inyecta» es a la vez biopoder y disciplina, ortopedia y condena.

Cristina: Todas manchadas del aceite y la vara. ${ }^{16}$

Julieta: Amiga, eso como que usted diga: me inyecté el veneno de la vida. Me lo comí. $\mathrm{Y}$ lo tengo.

Cristina: Es más, hubiera sido mejor otro veneno que este veneno. Porque con el otro no se ve, dice una... Diay, el venenazo, el bebe, ${ }^{17}$ dice una. ¿Me entendés?

Julieta: Ah sí.

Cristina: O sea que mucha gente se asusta con ese tema. Pero nadie te lo ve, ¿dónde está?

MF: ¿Pero fue el mismo mae ${ }^{18}$ que le hizo la vara a las dos?

Cristina: A todas.

Silvia: ¿A todas?

Julieta: Amiga, a todas. El mismo mae nos dañó a todas.

Es cierto que, en diálogo con Preciado (2008), diríamos que los cuerpos que estas mujeres desean no son producto exclusivo de su imaginación y de su individualidad; son el resultado de la historia, de siglos de intercambio de mujeres y dominación patriarcal, de la imposición de la heteronormatividad, de la voracidad de la estética capitalista, de la racionalidad biopolítica de la modernidad. Pero en aras del respeto a la autodeterminación de los cuerpos, en modo alguno podríamos por esto responsabilizarlas de las atrocidades que les infringieron sobre sus cuerpos.

Durante la observación etnográfica, acompañé a algunas compañeras a buscar atención en salud cuando sufrían complicaciones por los aceites en sus cuerpos. Con frecuencia escuché frases como: «eso que usted se puso», «el aceite

Vara: costarriqueñismo para decir cosa.

Expresiones coloquiales para referirse al VIH.

Mae: costarriqueñismo para nombrar a un fulano. 
que usted se inyectó», etc. Es un problema gramatical, un problema de la gramática de la violencia. Las mujeres trans, atrapadas en la manipulación mezquina de su deseo, son además culpabilizadas como si ellas fuesen las autoras intelectuales y materiales del biopoder.

MF: Pero eso se los ponía un médico, no ustedes...

Cristina: Igual no, no es ni culpa de ese mae, es culpa de las mismas chicas, de nosotras mismas.

Julieta: No hermana, pero es que es una necesidad. Es una necesidad. Amiga, eso no fue culpa de nosotras, porque fue una necesidad mental. Una necesidad mental que una persona...

Cristina: Fue una necesidad mental que nadie nos iba a llenarlo.

Los responsables directos de todas las muertes, y de que las sobrevivientes carguen hoy bombas de tiempo en sus cuerpos, son los médicos inescrupulosos y su mezquindad, y de forma indirecta la sociedad que alberga las condiciones para que estas atrocidades sean posibles y gocen de impunidad.

\section{Pedagogía de la crueldad sobre los cuerpos trans}

Fuera de la cárcel y el consultorio, la violencia alcanza a estas mujeres en la calle. La disciplina como dispositivo de poder no cesó en la década de 1970. Conforme avanzaron los años, las formas de control se fueron complejizando, nutridas por otros discursos de saber/poder. En las zonas de trabajo sexual los ataques son cosa de todas las noches. Cuando no es la policía, son hombres que utilizan los cuerpos de las mujeres trans para afirmar su masculinidad.

Mientras acompañaba los abordajes callejeros de la organización Transvida entre 2014 y 2017, escuché relatos de los abusos que sufrían por parte de la policía. Además de la burla constante de sus nombres registrales, la alusión a sus genitales, y la negación de su identidad femenina, registramos patadas, escupitajos, macanazos, sacudidas y abuso sexual. A algunas les rompían la cédula, y en seguida aducían que andaban indocumentadas para poder detenerlas. A una migrante le retuvieron por meses el pasaporte, dejándola sin el único documento que tenía para hacerle frente a la extrema vulnerabilidad. Una de ellas narró una perversa experiencia de tortura: mojaron con agua el cajón metálico de la patrulla y pusieron ahí el «chuzo eléctrico» para provocarle descargas sin dejar marcas. Estas y otras formas de violencia siguen marcando la cotidianidad de estas mujeres, mientras autoridades, transeúntes y vecindades voltean la mirada hacia otro costado de la ciudad.

Rita Laura Segato (2003) identifica la demonstración de fuerza y virilidad ante una comunidad de pares, como una de las expresiones dentro del carácter 
responsivo de la violación y sus interpelaciones. El estatus masculino exige la demostración constante de pruebas de potencia, la afirmación reiterada del poder y la dominación. Dice Segato:

«Masculinidad» representa aquí una identidad dependiente de un estatus que engloba, sintetiza y confunde poder sexual, poder social y poder de muerte [...]. No se trata de que el hombre puede violar, sino de una inversión de esta hipótesis: debe violar, si no por las vías del hecho, sí al menos de manera alegórica, metafórica o en la fantasía. (Segato 2003, 37-38)

Para entender la crueldad de los ataques que sufren las mujeres trans trabajadoras sexuales de San José, es necesaria una lectura desde la interseccionalidad. Las formas de violencia que enfrenta una mujer en este contexto son distintas a las que puede enfrentar una mujer trans con una condición de clase más privilegiada. Ni qué decir de las diferencias con la transfobia que puede enfrentar un hombre trans. Sin afán alguno de jerarquizar las opresiones, es necesario reconocer que existen diferencias abismales en las condiciones de posibilidad entre quienes habitan en el despojo material y quienes habitamos en zonas un poco menos hostiles.

Los sistemas de clase, género, sexualidad, edad y, en muchos casos, raza se amalgaman en los cuerpos de estas mujeres que siguen resistiendo a la tiranía de la opresión. Estamos ante lo que Sagot (2013) denomina un contexto de necropolítica, ${ }^{19}$ donde las mujeres (en este caso las mujeres trans) enfrentan formas extremas de violencia que resultan legitimadas por el sistema que se nutre de estas. En este sentido, señala que la calle en el contexto del trabajo sexual es uno de los escenarios del femicidio en la región:

aquí las víctimas son mujeres que se dedican al trabajo sexual y sus asesinos son generalmente clientes o proxenetas. También, algunas de estas mujeres pueden morir como blanco de acciones de exterminio o de «limpieza social». Este escenario tiene sus características particulares ya que las mujeres involucradas son altamente estigmatizadas y fácilmente cosificadas e incluso desechadas por una sociedad que ha construido un doble estándar en relación con el trabajo sexual. Asimismo, dado que en este escenario median transacciones comerciales, la posibilidad de que estas mujeres sean asumidas como propiedad de los hombres que se relacionan con ellas es muy alta, por lo que se incrementa el riesgo de femicidio. (Sagot 2013, 12) algunos cuerpos son vulnerables a la marginación, a la instrumentalización e incluso a la muerte. Un elemento central de la necropolítica es que los sistemas de estratificación también generan un biopoder basado en la noción de soberanía; es decir, en la capacidad de definir quién importa y quién no, quién es desechable y quién no» (Sagot 2013, 4). 
Violaciones, lanzamiento de objetos, secuestros, ataques, torturas, intentos de homicidio y trans-feminicidios se siguen registrando cada año (REDLACTRANS 2014). En marzo de 2016, las mujeres de esta comunidad lloraron el asesinato de Michelle, a quien dos hombres abordaron en la esquina en la que trabaja desde hacía varios años y la llevaron a un cuarto donde le propinaron 25 balazos. En 2017, el cuerpo de Kenisha de 15 años aparece en un matorral, a una cuadra de los Tribunales de Justicia en su pueblo natal.

Dice Segato sobre la pedagogía de la crueldad:

Toda violencia tiene una dimensión instrumental y otra expresiva. En la violación, toda violación, no es una anomalía de un sujeto solitario, es un mensaje de poder y apropiación pronunciado en sociedad. La finalidad de esa crueldad no es instrumental. Esos cuerpos vulnerables en el nuevo escenario bélico no están siendo forzados para la entrega de un servicio, sino que hay una estrategia dirigida a algo mucho más central, una pedagogía de la crueldad en torno a la cual gravita todo el edificio del poder. (Segato 2016, 79)

Desde la lógica de muchas leyes, la mayoría de las mujeres trans, en tanto no tienen una vagina ni pueden quedar embarazadas, ni siquiera serían susceptibles de ser violadas (Guillaumin 2005). Pero las mujeres trans, en Costa Rica como en todos países, son violadas cotidianamente. Sus cuerpos son penetrados: a veces por penes, a veces por piedras, a veces por balines. A veces las desvisten, las tocan, y no falta el policía que con la excusa de una requisa les corre el calzón y les saca el pene en una calle oscura.

Selina: Cuando una escuchaba venir las motos corríamos a escondernos. Una temblaba. Es que eran muchos, y pasaban y nos desvestían, los desgraciados, nos arrancaban la ropa. ¿Se acuerda cuando le arrancaron el brasier a usted, amiga, que la dejaron chinga ${ }^{20} \mathrm{y}$ usted lloraba? Pasan y nos tocan, nos empujan, nos arrastran.

Los ataques con un rifle de balines se han vuelto una problemática tristemente frecuente. Decenas de mujeres trans cargan en sus cuerpos balines incrustados tras alguno de estos ataques. En 2016, la situación llegó a un clímax preocupante, donde se presentaron cuatro ataques en un mes.

Ariela: De repente noté un carro Susuki color blanco que se acercó, y noté que el conductor del carro bajó su ventana a la mitad, alcancé a ver que me apuntaba con una arma. Al percatarme, reaccioné volteándome de espaldas al tipo y segundos después, seguido de escuchar el grito de odio del sujeto: ¡Playo hijueputa!, sentí un balín en la nalga izquierda. Enseguida el tipo huyó. 
Tania: El mae pasó y me descargó toda la pistola a mí. Me dio en las nalgas, en la espalda, en el brazo... Y después a mi amiga. Le disparó en todas las piernas, en la mano le metió uno.

Gabriela: Me ha pasado como 6, 7 veces. La última vez me pegó como unos 20 balines, calculo. Es que antes no se bajaba del carro, el mae solo tiraba los balines y si te lograba pescar te pegaba, pero ahora no, ahora tiene otras formas [...] se baja del carro y la persigue a una.

En la pedagogía de la crueldad el poder se ejerce tanto en el eje vertical de la violencia como en el horizontal, tanto en la dominación de un sujeto sobre otro, como en carácter expresivo y aleccionador que esto tiene para toda la sociedad.

Gabriela: La persona se baja del carro y tira los balines, me descarga toda la pistola, el magasín ${ }^{21}$ completo. Venía de tirarle balines a las otras chicas. [...] Anda siempre acompañado, andaba con otras dos personas, dos hombres.

Ariela: Después de disparar, dan vueltas para burlarse de nosotras y la policía no está.

Los agresores actúan siempre frente a un público, aun cuando anden solos. Su acción es una puesta en escena que ofrecen en el teatro de la masculinidad. Aun en las narrativas de quienes estaban solos en el momento de la agresión, puede leerse la interlocución con esos otros imaginados (Segato 2003). Los ataques que estas mujeres sufren no pueden entenderse solo como producto de la locura o la crueldad de unos cuantos hombres, sino como la expresión de la crueldad estructural, de la locura de una sociedad que se forja sobre la base de la dominación patriarcal y la exclusión social.

\section{La voluntad de existir}

Es indudable que estas mujeres fueron y siguen siendo víctimas de algunas de las prácticas más crueles del sistema penitenciario costarricense, del costado más mezquino de la medicina, de la furia rabiosa de las masculinidades tóxicas y del despojo carnicero del capitalismo neoliberal. Sin embargo, tampoco sería justo pensar que son víctimas pasivas. Guerreras incansables, ellas resistieron con ardiente valentía e insolencia los más fuertes castigos. Su mayor victoria es la persistencia. Hoy honran a sus muertas y celebran con orgullo la supervivencia de su estirpe que mantienen viva con sus cuerpos. Sonríen con complicidad cuando recuerdan los mecanismos que fueron ideando juntas para hacer frente a tanta letalidad. Humor, irreverencia, astucia, autodefensa y sororidad: fibras que tejen las redes de esas familias que germinan como hierbas en las grietas de la calle.

$21 \quad$ Magasín: cargador de las municiones del arma. 
¿Cuáles son sus estrategias y tácticas para escabullirse a la disciplina patriarcal, para desobedecerla? El arte de «paquetear» fue siempre una estrategia de resistencia. Paquetear es el nombre que se le da en la jerga trans costarricense al acto de pasar desapercibida como una persona cisgénero. ${ }^{22}$ Es un vocablo que proviene del contexto penitenciario, donde se utilizaba para nombrar algo falso.

Paquetear sigue siendo hoy una estrategia para alivianar el tránsito por los espacios públicos hostiles, aunque cada vez más mujeres trans cuestionan la imposición del paqueteo y señalan que termina convirtiéndose en un segundo closet, la cárcel de la existencia en el propio cuerpo. Sin embargo, entre las décadas de 1970 y el 2000, era una herramienta fundamental para escapar de la violencia policial:

Victoria: Yo pasaba desapercibida, entonces a mí no me cargaban, porque yo paquetaba. ¿Entiende la jugada? Yo pasaba así desapercibida. Cuerpo de mujer y femenina.

En aquellos tiempos tenían que paquetear hasta para comprar un almuerzo en la capital. Las esquinas, las casas de algunas que excepcionalmente contaban con apoyo familiar, y hasta un pequeño local que la primera organización trans del país, la Casa de las Orquídeas de la Noche, había logrado costear con apoyo de la cooperación internacional, se convirtieron en trincheras, en verdaderas escuelas autónomas, pedagogías intergeneracionales donde las que llevaban más tiempo «vestidas» compartían con las más «nuevas» sus saberes corporales sobre cómo vestirse, cómo modular la voz, cómo simular curvas y cómo caminar. En la actualidad, en los pasillos de la organización Transvida habita esta tradición, y es posible escucharlas compartiendo experiencias de maquillaje, consejos para cuidar el cabello y hasta recomendaciones de tiendas donde no las van a discriminar.

A pesar de estos esfuerzos colectivos de supervivencia, no todas logran paquetear. La violencia estructural se ensaña con más fuerza contra aquellos cuerpos a los que «se les nota», contra quienes hacen visible la transgresión a una masculinidad impuesta e indeseada, y evidencian que existe la vida más allá de las fronteras del género binario. A ellas especialmente les tocó defender su existencia con orgullo, irreverencia y ferocidad:

Alexa: Un paco un día me dijo a mí: está detenida. Le digo yo: ¿por qué? Y me dice: Porque me hizo esto. Y se reventó la camisa. Entonces yo agarré una botella y le dije: póngale eso al parte. [hace gesto de quebrarle la botella en la cabeza]. Porque llegó un momento que nosotras nos volvíamos agresivas con los mismos pacos. Y cuando los veíamos ya nos les cagábamos en la madre, pa que nos cargaran por algo, ya, legalmente.

22 Lo que en inglés suele nombrarse como «passing». 
En la cárcel intentaron despojarlas de su feminidad, les rapaban el pelo, las vestían con ropas anchas y hediondas, pero ellas resistieron. Cortaron las ropas para hacer prendas sensuales, idearon formas de obtener pelucas, hicieron trajes de gala con harapos, maquillajes artesanales. Adentro de la cárcel, organizaron certámenes de belleza, que si bien no eran iguales a los que organizaban afuera (que constituían una verdadera oda a la feminidad, en espacios seguros de ellas para ellas, donde eran a la vez concursantes, jurado y público), dentro del centro penitenciario se convertían en una defensa colectiva, irreverente y pomposa de su identidad. Los certámenes culminaban con un gran baile, al ritmo de basureros convertidos en tambores y maracas, donde las chicas festejaban su derecho a la alegría y a la feminidad elegida que nadie lograría arrancarles.

A pesar de estas conquistas en la batalla por la defensa de su existencia, la prisión seguía siendo un espacio hostil que buscaban evitar. Entre sonrisas y tazas de café comparten recuerdos de complicidad y resistencia: cómo escondían entre varias a las compañeras perseguidas, cómo juntaban dinero para pagarle la fianza a alguna de sus amigas, o hasta cómo le entregaban un porro y el plato que llevaban para cenar ese día a una compañera que estaba a punto de ser detenida, para que sobreviviera la noche en el calabozo. Algunas comenzaron a utilizar la seducción como estrategia, no solo para salvarse a sí mismas, sino en clave sororaria, para liberar a sus compañeras. Cuenta una veterana que ella la apodaban la «paquera»:

Sandra: La paquera. Me encantaban los pacos. Entoes, a ellas, a todo el resto las detenían, y a mí me dejaban suelta. Entoes, yo aprovechaba el momento en que ellos se iban por allá a detener a alguna, y abría el cajón.

Aprendieron a abrir el cajón de la patrulla con una gasilla, y a leer el movimiento del motor en el momento exacto en que se detenía en un semáforo en rojo, para abrir de par en par las puertas y salir corriendo todas en múltiples direcciones buscando camuflarse entre las sombras de la ciudad.

«Tocan a una y reaccionamos todas»: una consigna feminista que estas mujeres trans han practicado con cariño y valentía. Esta es sin duda la clave de su supervivencia, de su voluntad de existir, de su persistencia contra un sistema letal que ha buscado por décadas aniquilarlas. Hoy, las herederas de esta colectividad de mujeres trans están organizadas, informadas, empoderadas y hartas. No les asusta luchar por sus derechos y han ido perdiendo el miedo de enfrentar a sus agresores. Están decididas a señalarlos, denunciarlos, confrontarlos y descolocarlos, y a acompañarse unas a otras en el proceso. Como una red que sostiene la existencia, esta jauría desjaulada busca colectivizar sus resistencias siguiendo la enseñanza de sus madres y sus abuelas de calle: juntas son más fuertes. El miedo ha disminuido hoy su efecto disciplinar, y estas mujeres insumisas e insurrectas, se organizan para sumarse a las luchas feministas poniendo sus cuerpos, sus voces y sus saberes para desmontar la misoginia, el clasismo, la transfobia y la pedagogía de la crueldad. 


\section{Referencias bibliográficas}

Biglia, Barbara, y Bonet-Martí, Jordi. 2009. «La construcción de narrativas como método de investigación psico-social. Prácticas de escritura compartida». Forum Qualitative Sozialforschung / Forum: Qualitative Social Research, 10(1), Recuperado de: http://nbnresolving.de/urn:nbn:de:0114-fqs090183

Crenshaw, Kimberle. 1989. «Demarginalizing the Intersection of Race and Sex: A Black Feminist Critique of Antidiscrimination Doctrine, Feminist Theory and Antiracist Politics». University of Chicago Legal Forum. Volumen 1989. Número 1, Artículo 8. Recuperado de: http://chicagounbound.uchicago.edu/uclf/vol1989/iss1/8

Foucault, Michel. 2002. Vigilar y castigar. Argentina: Siglo XXI.

Foucault, Michel. 2003. El poder psiquiátrico, Curso 1973-1974. Buenos Aires: Fondo de Cultura Económica.

Foucault, Michel. 2008. Seguridad, territorio, población. Buenos Aires: Fondo de Cultura Económica.

Fournier, Mar. 2017. Género, Clase y Afectividad: vínculos y comunicación en una comunidad de trans. Tesis para optar por el grado de Maestría Académica en Comunicación y Desarrollo. Universidad de Costa Rica.

Guillaumin, Colette. 2005. «Práctica del poder e idea de Naturaleza». In El patriarcado al desnudo. Tres feministas materialistas, editado por Ochy Curiel y Jules Falquet, 19-56. (Comp). (2005). Buenos Aires: Brecha Lésbica.

OIM - Organización Internacional para las Migraciones. 2016. Migración y poblaciones lesbianas, gais, bisexuales, trans e intersexuales (LGBTI): módulo para la capacitación y sensibilización de instituciones públicas, organizaciones sociales, colectivos y activistas LGBTI en la región mesoamericana. San José, C.R.: OIM.

Preciado, Paul [Beatriz]. 2008. Testo Yonqui. España: Espasa-Calpe.

REDLACTRANS. 2014. Informe sobre el acceso a los derechos económicos, sociales y culturales de la población trans en Latinoamérica y el Caribe. Recuperado de: http://redlactrans.org.ar/ site/wp-content/uploads/2015/03/Informe\%20DESC\%20trans.pdf

Sagot, Montserrat. 2013. «El femicidio como necropolítica en Centroamérica». LABRYS, Études Féministes/ Estudos Feministas, (24). Recuperado de: https://www.labrys.net.br/ labrys24/feminicide/monserat.htm

Segato, Rita Laura. 2003. Las estructuras elementales de la violencia. Buenos Aires: Universidad Nacional de Quilmes.

Segato, Rita Laura. 2016. La guerra contra las mujeres. Madrid: Traficantes de sueños.

Mar Fournier Pereira. Activista transfeminista. Licenciatura en Psicología, Maestría Académica en Comunicación y Desarrollo por la Universidad de Costa Rica. Docente en la Universidad de Costa Rica (UCR). Doctorante en Filosofía, Université Lille 3, CECILLE (59653 Lille, Francia). En diálogo con la actividad militante, ha trabajado en docencia e investigación en la Universidad de Costa Rica desde 2010, en el área de psicología social, investigación, género y sexualidades.

Correo electrónico: mar.fournierp@gmail.com

Artículo recibido en 15 de mayo de 2018 y aprobado para publicación en 4 de septiembre de 2018. 